East African Medical Journal Vol. 79 No. 2 February 2002

VERBAL AUTOPSY IN ESTABLISHING CAUSE OF PERINATAL DEATH

N. Iriya, MD, MMed (Paed), Bugando Medical Centre, Mwanza, Tanzania, K. P. Manji, MBBS, MMed (Paed) and R.L Mbise, MBChB, MMed., M.Sc., Department of Paediatrics and Child Health, Muhimbili University College of Health Sciences, P.O. Box 65001, Dar es Salaam, Tanzania.

\title{
VERBAL AUTOPSY IN ESTABLISHING CAUSE OF PERINATAL DEATH
}

\author{
N. IRIYA, K. P. MANJI and R.L MBISE
}

\begin{abstract}
Introduction: Perinatal mortality is a sensitive indicator of health status of a community and is also highly amenable to intervention. The causes of perinatal deaths in developing countries are often difficult to establish. Verbal autopsy has been used in several countries for children and adults, but seldom for perinatal cause.

Objective: To establish the cause of perinatal deaths using verbal autopsy.

Design: Community-based cross-sectional, retrospective study to identify perinatal death over a one year period from July 1996-June 1997. Comparison was made with hospital records. An algorithm of signs and symptoms was used by trained personnel to identify the cause of perinatal death. The duration of collection of data was six months (August 1996January 1997).

Setting: Hai district of Kilimanjaro region in Tanzania.

Subjects: All perinatal deaths within one year.

Results: The perinatal mortality was 58 per 1000 (121 deaths and 2088 live births). Verbal autopsy could establish the cause of death in 105 of the 121 deaths. Hospital records showed 79 deaths indicating that 42 deaths probably occurred at home. Among the 79 available hospital records, the cause of death could be established in only $30(38 \%)$. The causes of postnatal death were compared between the verbal autopsy and hospital records. There was a good correlation between the same, however only 18 records were available from hospital among the total 31 postnatal deaths. The specificity of determining cause of death using verbal autopsy was $100 \%$ and sensitivity $61 \%$.

Conclusion: The commonest causes of perinatal deaths were related to obstetric care, therefore interventions to curb perinatal mortality should be directed to improvement of obstetric care. Verbal autopsy is a simpler and more sensitive tool in establishing the cause of perinatal death than hospital records in a rural district of Tanzania. Large-scale studies are needed to validate this.
\end{abstract}

\section{INTRODUCTION}

Perinatal mortality rates (PMR) are considered a sensitive indicator of a community's health status(1). In Tanzania, like in many developing countries, the PMR is high and is estimated to be $58-91$ per 1000 live births. However, the causes of perinatal deaths is not much known for various reasons, one of which is lack of proper hospital records and secondly, many deaths occur at home(2).

When death occurs at home or in a hospital facility where information is poorly recorded a postmortem interview with the family or health worker can be done to obtain possible or nearest cause of death. This interview with the aim of establishing cause of death is called verbal autopsy(3).

Verbal autopsy (VA) has been used in various settings to establish the cause of death and it has been found to be a useful tool(4-7). Few studies have however used this tool for determination of causes of perinatal deaths.

Therefore this study was undertaken to identify the causes of perinatal deaths and compare with hospital records.

\section{MATERIALS AND METHODS}

This was a community-based cross-sectional, retrospective analysis of all perinatal deaths, which occurred between July 1995 to June 1996. The data were collected between August 1996 to January 1997.

Site: Hai district of Tanzania lies on the southwest slopes of Mount Kilimanjaro. It has an area of 13,000 square kilometres and a population of 260,000 . The population growth rate is $2.8 \%$ per year. There are about 38,200 households with an average family size of 5.2. There are two district hospitals and four-health centres. About $47 \%$ of the population are below 15 years age.

Data collection and analysis: Local leaders (called ten cell leaders) assisted to identify perinatal deaths. This was a houseto-house visit, whereby $200-220$ houses were visited daily. This also helped to identify the number of deliveries that occurred. Three trained enumerators assisted in identification of the perinatal deaths. These enumerators were trained for a period of three weeks in interpretation of physical signs and symptoms. All the enumerators were $\mathrm{MCH}$ Aides who lived in the community. They arranged suitable time for visiting the household where a perinatal death had occurred. About 10-15 households were visited daily. The verbal autopsy was administered after translation into Swahili language. This Swahili version was pre-tested and was found to be appropriate. Although the biological mother was interviewed, in case of maternal death, the next of kin who was 
involved in the care of the baby was interviewed (usually the grandmother).

The available information on the events occurring at around the death of the baby was listed in the VA form. A neonatologist (KA) then assessed each of these independently and compared with the assessment by another specialist to reach a concensus. The causes of death were grouped into five categories using the Wiggleworths classification(8). Examples of some are: (i) Born earlier before the expected date, was very small, below 2.5 kilograms, had difficulty in breathing at birth, was grunting and needed oxygen. Baby died at the age of two days. This was most likely to be associated with preterm delivery and; (ii) Term baby, delivered after a prolonged labour, did not cry at all at birth, failed to breathe. Required to be pumped with air, was given oxygen for several hours. Could not respond and died within 24 hours. This is most likely perinatal asphyxia related death.

Comparison of the mortality data obtained by this VA was done with the available hospital statistics when available.

\section{RESULTS}

There were 2088 births and 121 perinatal deaths. Thus, the perinatal mortality rate was 58 per 1000 live births. The timing of death and source of establishing the cause of death is indicated in Table 1. The number of deaths recorded from the community survey were 121 , while the hospital records showed 79 deaths. Thus, 42 (35\%) deaths were not recorded in the hospital.

Table 1

Timing of death and source of information

\begin{tabular}{lcccccc}
\hline Description of death & \multicolumn{5}{c}{ Source of information } \\
& $\begin{array}{l}\text { Verbal autopsy } \\
\text { Known }\end{array}$ & Unknown & $\begin{array}{c}\text { Hospital records } \\
\text { Known }\end{array}$ & $\begin{array}{c}\text { Unknown } \\
\text { or not } \\
\text { available }\end{array}$ \\
& & & & \multicolumn{4}{c}{ Total } \\
\hline Fresh still birth & 54 & 13 & 5 & 16 & 88 \\
Macerated still birth & 20 & 3 & 7 & 17 & 47 \\
Postnatal death & 31 & - & 18 & 16 & 65 \\
\hline Total & 105 & 16 & 30 & 49 & 200
\end{tabular}

Among the 79 hospital deaths, cause of death was available in $30(38 \%$ ) cases, while from the verbal autopsy, the causes of death were established among 105 out of 121 $(87 \%)$. Thus, it is three times more likely to establish a cause of death from VA than from hospital records. The level of agreement between the verbal autopsy and hospital records appeared acceptable. The sensitivity and specificity for still births was $80 \%$ and $76 \%$ respectively. While the sensitivity and specificity for postnatal births was $61 \%$ and $100 \%$ respectively.

The postnatal deaths were further stratified using the simplified Wiggleworths classification as indicated in Table 2 .
Talke 2

Causes and time of perinatal deaths from the community

\begin{tabular}{lcccr}
\hline Cause & \multicolumn{5}{c}{$\begin{array}{r}\text { Timing } \\
\end{array}$} & $<2$ hrs & 24hrs-3 days & $>$ 3days-7days & Total \\
\hline Prematurity & 2 & 7 & 3 & 12 \\
Birth asphyxia & 3 & 3 & - & 6 \\
Infection & - & - & 10 & 10 \\
Congenital anomaly & - & 2 & - & 2 \\
Others & 1 & - & - & 1 \\
\hline
\end{tabular}

The causes of deaths from the 18 available hospital records were prematurity in five, asphyxia in eight, infection in four and bleeding in one case. These causes were then tallied with the verbal autopsy. Except for asphyxia, which had a correlation of $75 \%$, all others had a concordance of $100 \%$.

\section{DISCUSSION}

This community-based survey to determine the cause of perinatal death was found to be more effective and relevant than the hospital based statistics because records were not available for 33 out of 121 deaths (27\%). The reasons could be several. First, many perinatal deaths may take place at home and therefore there will be no hospital statistics; secondly in a primary health centre, record keeping and retrieving records after one year is not an easy task.

Verbal autopsy has been used in several studies to determine the cause of death. A prospective study. in Nepal used a similar method to identify causes of perinatal deaths. The perinatal mortality rates in the two settings were 42.5 and 96.2 per 1000 live births. The most common identifiable causes of death were asphyxia, low birth weight and infections, although there were many unexplained deaths(9). In our survey, using the VA, we found that 90 out of 121 deaths were related to obstetric causes. This information can be used to direct resources towards specific obstetric related interventions.

Likewise, in Namibia, verbal autopsy was used to establish the cause of death in 135 deaths of children aged under five. Two hundred and forty three diagnoses were made including malnutrition in 77 , diarrhoea in 73 , pneumonia in 36, malaria in 33 and measles in 24. The sensitivity and specificity of various algorithms of the reported signs and symptoms were compared with the medical diagnosis. The study revealed that it could be useful to ascertain the leading causes of death although it has some limitations(10). Similar findings were obtained from a study in Malawi(11).

In a validation study of 295 deaths in children in Kenya, data derived algorithms and experts' algorithms for VA yielded similar levels of accuracy, except for malaria(12). In our study, from the available 18 postnatal causes of death, the concordance was $100 \%$, indicating 
that VA can be used effectively. One of the reasons of such a high concordance is that, even in the hospital setting, the causes of death are usually dependent on an algorithm rather than diagnostic facilities. For example, a neonate with umbilical cord sepsis and poor feeding with convulsions is likely to be diagnosed to have septicaemia and meningitis (infection). When using the VA algorithm for this case, a similar diagnosis will be obtained. Secondly, the causes of perinatal deaths are relatively limited, such as when using the Wiggleworths classification(8). This narrows down the causes of postnatal deaths and allows better reporting. However, despite narrowing the classification, causes of perinatal deaths are not forthcoming from hospital statistics due to the lack of record keeping and retrieval system.

In conclusion, verbal autopsy may be useful in identifying causes of perinatal deaths in a rural community setting. We recommend that there is a need to have a good data recording and retrieval system in hospitals. There is also a need to validate VA in a larger study as a tool to establish perinatal deaths.

\section{ACKNOWLEDGEMENTS}

To the UNICEF and COSTECH-Tanzania for funding the project of perinatal mortality and to Dr. R. r. Risenge for reviewing the manuscript.

\section{REFERENCES}

1. World Health Organization. The state of the worlds children. 1996; Geneva.

2. Kitange H., Swai A.B., Masuki G., Kilima P.M., Alberti G. and McLarty D.G. Perinatal mortality in rural Tanzania. Wld. Hlth. Org. Forum 1994; 15:82-4.

3. Essential Newborn Care. Report of a technical working group. Trieste, April 1994. WHO/FRH/MSM/96.13: 14-15.

4. Snow R.W., Armstrong S.R.M. and Foster D. Childhood deaths in Africa. Uses and limitations of verbal autopsy. Lancet. 1992; 340: 351355.

5. Kalter R. Validation of postmortem interviews to ascertain selected causes of death in children. Int. J. Epidem. 1990; 19:380-386.

6. Alfonso P.L. The accuracy of clinical histories given by mothers of seriously ill African children. Ann. trop. Paediat. 1987; 7:187-9.

7. Mirza N.M., Macharia W.M., Wafula G.M., Agwanda R. and Onyango F.E. Verbal Autopsy: a tool tor determining cause of death in a community. East Afr. Med. J. 1990; 67:693-698.

8. Wiggleworth J. Monitoring Perinatal Mortality: A pathophysiological approach. Lancet 1980; II: 684-686.

9. Geetha T., Chenoy R., Stevens D. and Johanson R.B. A multicentre study of perinatal mortality in Nepal. Paediat. Perinat. Epidem. 1995; 9: 74-89.

10. Mobley C.C., Boerma J.T., Titus S., Lohrke B., Shangula K. and Black R.E. Validation study of verbal autopsy method for causes of childhood mortality in Namibia. J. trop Paediat. 1996; 42:365-9.

11. Nykanen M., Tamaona W., Cullinan T., Van Oosterzee V. and Ashorn P. Verbal autopsy as a technique to establish causes of infant and childhood mortality. East Afr. Med. J. 1995; 72:731-4.

12. Quigley M.A., Armstrong S.J.R. and Snow R.W. Algorithms for verbal autopsies: a validation study in Kenyan Children. Bull. Wld. Hlth. Org. 1996; 74:1147-54. 